\title{
História da Ciência \& COVID-19: Oportunidades e Constrangimentos no Ensino em Portugal
}

\author{
History of Science \& COVID-19: \\ Teaching opportunities and constraints in Portugal
}

\begin{abstract}
Joana Torres, Instituto de Estudos Superiores de Fafe, Portugal (joana.torres@fc.up.pt)
Isilda Rodrigues, Universidade de Trás-os-Montes e Alto Douro, Portugal
\end{abstract}

\begin{abstract}
Resumo: A pandemia que vivemos, provocada pela disseminação do coronavírus SARS-CoV-2, tem um impacto indubitável nas nossas rotinas e na nossa forma de pensar o que, consequentemente, vem afetando também todo o funcionamento das atividades letivas. Desta conjugação, a ciência acabou por ganhar um papel reforçado na nossa sociedade, uma vez que se tornou crucial à compreensão do vírus, da doença e das suas implicações na nossa vida diária. No que concerne ao ensino das ciências, a pandemia permitiu reforçar a necessidade dos nossos alunos compreenderem como a ciência se desenvolve (natureza da ciência) e também a importância de desenvolverem competências que lhes permitam superar os mais variados desafios, fundamentais para tomarem decisões informadas e conscientes. Neste sentido, consideramos que o recurso ao contexto atual de pandemia, assim como, ao do contexto histórico de pandemias anteriores, pode ajudar a potenciar aprendizagens nos nossos alunos de todos os níveis de ensino.

Pelo exposto, e de forma a compreender como é que a história da ciência nomeadamente a história das pandemias, e o contexto pandémico em que vivemos foram explorados nas aulas em Portugal - foi elaborado e validado um inquérito por questionário. Os questionários foram enviados por email aos professores do Ensino Básico e do Ensino Secundário, para serem preenchidos de forma anónima em formato digital. Participaram no estudo 58 professores, dos vários grupos disciplinares, da região norte do país.

Verificámos que um número substancial de professores refere ter recorrido mais à história das pandemias, tendo em conta o contexto atual, referindo que os alunos se revelaram motivados. Apesar das dificuldades impostas pela COVID-19, consideramos que a Educação em Ciências tem uma importância acrescida perante a situação pandémica atual, sendo a formação de professores e o desenvolvimento de materiais/recursos didáticos fundamentais para uma abordagem da história das pandemias e da situação pandémica atual consentânea com os desígnios da investigação educacional.
\end{abstract}

Palavras-chave: Aprendizagem, COVID-19, Ensino da História da Ciência, História da Ciência, Pandemias. 
Abstract: The current pandemic that we all face, caused by the spread of the SARSCoV-2 coronavirus, has an unquestionable impact on our routines and way of thinking, also affecting the course of school activities. Science becomes even more noticeable in our society, as it became crucial to understand the virus, the disease, and its implications in our daily life. When it comes to science teaching, the pandemic highlighted for the need of our students to understand how science develops (nature of science) and to develop competences that allow them to overcome a diversity of challenges and to take informed and conscious decisions. In this way, resorting to the current pandemic context, as well as to the historical pandemic contexts may enhance students' learning of all educational levels.

Therefore, it was constructed and validated a questionnaire to understand how history of science, namely the history of pandemics, as well as the current pandemic context were focused on classes in Portugal. Questionnaires were sent by email, asking teachers from basic to secondary school to anonymously complete them online. This study involved 58 teachers of different subjects from the North of Portugal.

We verified that a substantial number of teachers referred to have resorted more to the history of pandemics, taking into account the current context, indicating that students revealed motivated. Despite the challenges presented by COVID-19, we consider that Science Education came out of this pandemic with a revamped relevance, being teachers training and the development of materials/didactical resources fundamental for a different approach on pandemic history and the current pandemic situation, in order to better be aligned with Science Education research.

Keywords: Learning, COVID-19, History of Science Teaching, History of Science, Pandemics.

\section{Introdução}

A COVID-19 é uma doença infeciosa causada pelo vírus SARS-CoV-2, que passou a ser considerada como uma pandemia a 11 de março de 2020 (WHO, 2020), tendo em conta a sua vasta propagação mundial e o facto de afetar um grande número de pessoas (Cook, 2020; Parihar, Kaur, \& Singh, 2021). Fenómeno de tal magnitude afetou incontornavelmente várias dimensões da vida em sociedade, tendo interferido de forma direta na nossa saúde, assim como nas atividades turísticas, económicas, sociais e culturais, afetando também de forma determinante a educação (Harangi-Rákos, Ștefãnescu, Zsidó, \& Fenyves, 2022; Torres, 2021). Neste contexto, a escola foi, de facto, forçada a reinventar-se num curto espaço de tempo (Revel Chion \& Adúriz-Bravo, 2021), o que afetou necessariamente todos os alunos, especialmente os mais vulneráveis (OECD, 2020). No que concerne à educação em Portugal, foram vários os desafios que se colocaram aos alunos e aos professores dos vários níveis de ensino, assim como aos próprios encarregados de educação e familiares, tendo havido uma rápida adaptação às várias situações 
colocadas pela pandemia, nomeadamente ao ensino à distância (Fernandes, Machado, Alves \& Aguiar, 2021).

Por um lado, toda esta situação pandémica conferiu um destaque particular à Ciência, lançando também alguns reptos à própria educação em Ciências. $\mathrm{Na}$ realidade, para tomar decisões informadas, conscientes e responsáveis, perante todos os desafios que a própria pandemia coloca, é fundamental que os alunos desenvolvam conhecimentos sobre a mesma, desenvolvam competências e que compreendam a Ciência, a sua importância e as suas características, particularmente como esta se relaciona com o contexto social, económico e político (Revel Chion \& Adúriz-Bravo, 2021; Moura, Nascimento \& Lima, 2021; Torres, 2021).

Por outro lado, também a comunicação em Ciências se revelou e revela fundamental, ao contribuir para a literacia e tomada de decisões informadas da comunidade em geral, sendo, neste âmbito, determinante promover a informação e combater a desinformação. Como refere Bichara (2021), é de acrescentar que é importante que a informação fidedigna sobre a COVID-19 seja acompanhada com informação acerca de aspetos da natureza da ciência, que permita que os cidadãos coloquem o conhecimento em rápida evolução em perspetiva e que confiem mais na ciência, refletindo-se na sua opinião, escolhas e ações.

Desta forma, consideramos que todos estes desafios que atualmente a pandemia nos tem imposto, podem também servir de mote a uma melhor compreensão da Ciência e da sua Natureza $(\mathrm{NdC})$, quer através da análise das múltiplas dimensões da COVID-19, quer através da análise da história de outras pandemias que marcaram a história da humanidade (Reiss, 2020; Torres, 2021). Adicionalmente, toda esta análise e discussão em torno da COVID-19 e de outras epidemias permitirá o desenvolvimento de competências e o desenvolvimento do espírito crítico e científico, permitindo uma análise/reflexão/discussão acerca de múltiplos aspetos, tais como a intervenção humana no nosso planeta, a importância das vacinas, dos antibióticos e a importância de sustentarmos a nossa opinião e ações em informação fidedigna. Contribuindo, deste modo, também para o desenvolvimento da literacia em saúde.

Tendo em conta as oportunidades descritas, e desenvolvidas posteriormente no nosso enquadramento teórico, consideramos de suma importância compreender como é que a história da ciência (HC) - nomeadamente a história das pandemias e o contexto pandémico em que vivemos foram explorados nas aulas em Portugal, qual a recetividade dos alunos à abordagem da história das pandemias, assim como analisar algumas das principais dificuldades e benefícios que advieram da situação pandémica nas atividades letivas. 
De seguida, faremos uma breve abordagem à importância da natureza da ciência e apresentaremos alguns apontamentos sobre a história de algumas epidemias e pandemias.

\section{Natureza da Ciência}

Apesar das controvérsias em torno do conceito "Natureza da Ciência" (NdC) e dos aspetos da $\mathrm{NdC}$ que devem ser abordados em sala de aula, podemos dizer, de uma forma geral, que a $\mathrm{NdC}$ se refere às características do conhecimento científico, que se relacionam com a forma como ele é produzido (Acevedo-Díaz \& GarcíaCarmona, 2016; Lederman, Antink \& Bartos, 2014; Torres \& Vasconcelos, 2021). Por outro lado, são vários os autores (Abd-El-Khalick, 2006; Lederman, Abd-ElKhalick, Bell \& Schwartz, 2002) que consideram que há aspetos relevantes e acessíveis da $\mathrm{NdC}$ que devem ser trabalhados em sala de aula e na formação de professores, nomeadamente: o facto do conhecimento científico ser provisório; empírico; parcialmente subjetivo; influenciado pela imaginação e criatividade dos cientistas e influenciar e ser influenciado pelo contexto onde se desenvolve. Adicionalmente, consideram ser importante que se compreenda a distinção entre observação e inferência, e entre teorias e leis; sendo também crucial que se compreenda que não existe um único método científico. Estes aspetos, apesar de não serem unânimes, são consensuais entre muitos investigadores, nomeadamente os já referidos, sendo considerados fundamentais como um ponto de partida para a construção de uma imagem adequada de Ciência (Kampourakis, 2016; Torres \& Vasconcelos, 2015). A compreensão da NdC é, assim, considerada fundamental para que os alunos sejam cientificamente literatos e para que compreendam o funcionamento, as limitações e potencialidades da Ciência, permitindo que os alunos desenvolvam, entre outras coisas, o seu espírito crítico e científico e que tomem decisões informadas e conscientes (Cheung, 2020; Kampourakis, 2016).

Se, por um lado, a situação pandémica em que vivemos exige que os alunos desenvolvam conhecimento e sejam cientificamente literatos para atuar de forma informada, consciente e responsável, por outro lado, fornece uma oportunidade para analisar e discutir vários aspetos acerca da $\mathrm{NdC}$. Na realidade, ao analisar a situação pandémica atual, é possível compreender, entre outros aspetos, que a evolução da ciência está muito associada aos interesses do ser humano (com esta situação foram vários os estudos e projetos desenvolvidos para compreender melhor a doença e para desenvolver terapêuticas, nomeadamente vacinas e antivirais) e que o conhecimento científico se altera e está muito dependente de financiamento (pudemos assistir à abertura de vários concursos para financiamento de uma diversidade de projetos relacionados com a COVID-19), sendo muito afetado pela realidade envolvente 
(foram vários os estudos desenvolvidos acerca do impacto da pandemia na educação, na economia, entre outros). De facto, todo este cenário atual permite compreender a relação intrincada que existe entre a ciência, a sociedade, a economia e as decisões políticas (Moura, Nascimento \& Lima, 2021; Revel Chion \& Adúriz-Bravo, 2021).

\section{Apontamentos sobre a História de algumas Epidemias e Pandemias}

Foram várias as epidemias e pandemias que assolaram a humanidade, que acarretaram milhões de mortes e consequências a nível de saúde, mas também a nível social, económico e político (Toapanta, 2021). Neste sentido, a partir da análise histórica das mesmas, podemos tirar algumas lições importantes que nos auxiliam a lidar com a situação pandémica atual, assim como com eventuais situações futuras desta natureza que possam surgir (Cook, 2020; Parihar, et al., 2021).

Apesar das diferentes pandemias resultarem de diferentes fatores e agentes patogénicos, estas refletem alterações rápidas nos estilos de vida e atividades humanas (Dobson, \& Dobson, 2017). Com efeito, é possível afirmar que muitas delas se relacionam, de uma forma geral, com a falta de condições sanitárias e com grandes ajuntamentos, nomeadamente através da existência de cidades superpovoadas (Dobson, \& Dobson, 2017; Parihar, et al., 2021), sendo igualmente as deslocações promovidas pela guerra um fator propulsor da propagação de doenças. Como exemplo, vários estudos indicam que muitos dos soldados de Napoleão foram atingidos por doenças infeciosas, facto que contribuíra para a sua retirada da Rússia (Dobson, \& Dobson, 2017; Raoult, et al., 2006). Se atualmente contamos, por um lado, com o avanço da medicina e com o aumento das condições sanitárias em muitos países (ainda que existam algumas exceções, infelizmente!), que permitem limitar a propagação de doenças, por outro lado a propagação de doenças, como a COVID-19, é facilitada pelo aumento da população e a facilidade com que esta se interconecta.

A Peste Negra (século XIV) foi uma pandemia que teve um impacto devastador na humanidade, sendo responsável pela morte de cerca de 50 milhões de pessoas na Europa, daí ser também designada como "the Great Mortality" (Dobson, \& Dobson, 2017), conduzindo também a profundas alterações económicas, políticas e sociais (Roos, 2020). Propagou-se a partir da Ásia, através de rotas comerciais, sendo favorecida pela falta de condições de salubridade, pela existência de locais superlotados, pela qualidade de vida das pessoas e também devido ao desconhecimento da doença - formas clínicas, prevenção e cura (Callegari, Callegari, \& Cattani, 2020; Dobson, \& Dobson, 2017; Toapanta, 2021). Na realidade, o conhecimento médico revelava-se impotente no combate à pandemia, sendo que para escapar à infeção era evitado o contacto com pessoas infetadas e objetos contaminados (Tognotti, 2013). 
Neste sentido, Cook (2020) apresenta-nos um exemplo da povoação de Eyam, em 1665, que foi atingida por um surto de peste bubónica e que decidiu fazer uma quarentena, durante a qual ninguém podia entrar ou sair da povoação, para impedir a propagação da doença. Para além de não se deslocarem para fora da povoação, os habitantes mantinham a distância social e o isolamento, sendo que os bens para os habitantes eram deixados nos limites da povoação. As moedas eram lavadas em água ou vinagre e os médicos também possuíam um equipamento de proteção individual, que consistia numa bata e numa máscara em forma de bico de pássaro preenchida com ervas (para neutralizar a praga, mas também para abafar os maus odores). Apesar do presente exemplo revelar um enorme sacrifício da população, é demonstrativo, por outro lado, da importância que a religião acabou por ter, influenciando, inegavelmente, as decisões supra descritas.

A varíola também tirou partido de grandes agregados populacionais para se propagar, sendo particularmente virulenta no século XVIII. Esta doença cobria as suas vítimas com manchas que se transformavam em crostas, deixando cicatrizes profundas na pele e lesões no nariz e na boca, sendo frequentemente letal. Esta doença e os esforços que foram tidos para a controlar estimularam algo muito importante para a medicina - a vacinação. Edward Jenner (1749-1823), após observar que as pessoas que haviam sofrido de varíola bovina resistiam à varíola, desenvolveu a vacina que se revelou extremamente eficaz para derrotar esta terrível doença viral. No entanto, à semelhança do que acontece atualmente, também nesta situação surgiram muitos movimentos anti-vacinação, apesar da importância que hoje lhe é atribuída (Cook, 2020; Dobson, \& Dobson, 2017; Smith, 2011).

Com a revolução industrial, as cidades tornaram-se densamente povoadas e poluídas, potenciando o desenvolvimento de pandemias. A cólera teve origem na Índia e atingiu as cidades insalubres da Europa através das redes de comércio que ligavam as várias cidades. Esta doença provocava vómitos, diarreia e morte rápida por desidratação e levantou alguma polémica entre os especialistas relativamente à forma como se propagava. Apesar de se considerar que a cólera se propagava através de miasmas, John Snow (1813-1858) conseguiu demonstrar que se propagava através de água contaminada com fezes (Brody, Rip, Vinten-Johansen, Paneth, \& Rachman, 2000; Cook, 2020; Dobson, \& Dobson, 2017). Snow havia já observado a cólera em 1831, tendo desenvolvido alguns estudos nos anos posteriores. Quando o surto de cólera atingiu Londres em 1854, conseguiu demonstrar que a cólera se transmitia através da água que as pessoas bebiam e não pelos miasmas no ar que respiravam (Brody, et al., 2000; Cook, 2020; Dobson, \& Dobson, 2017). No final do século XIX, os investigadores isolaram a bactéria causadora da cólera Vibrio cholerae, permitindo um grande controlo da doença (Cook, 2020). 
A Gripe Espanhola (1918-1919), pandemia muito letal que foi causada por um vírus $(\mathrm{H} 1 \mathrm{~N} 1)$ que ataca o tecido pulmonar, também contou com o contributo da deslocação das tropas na I Guerra Mundial, fracas condições sanitárias e locais sobrepovoados para a sua disseminação (El-Dine, \& Mello, 2021). Contrariamente ao que o nome parece indicar, a Gripe Espanhola não teve origem em Espanha, sendo que o seu nome se deveu ao facto de a imprensa espanhola divulgar, sem censura, o avanço e impacto da pandemia (Dobson, \& Dobson, 2017; El-Dine, \& Mello, 2021; Honigsbaum, 2020). Na realidade, apesar das controvérsias relativas à origem da pandemia, pensa-se que esta terá tido origem nos Estados Unidos da América, tendo-se propagado para a Europa através dos militares. A sua elevada letalidade deveu-se ao facto de surgirem doenças bacterianas associadas à doença viral (Villar, 2020). Uma vez que não havia antibióticos ou antivirais, foram tomadas medidas (não farmacológicas) para prevenir a doença, que ainda hoje são conhecidas e praticadas, como a proibição de encontros públicos; o fecho de escolas, lojas e igrejas; a desinfeção de casas e estradas; a proibição de apertos de mão; a obrigatoriedade do uso de máscara (embora sem os critérios de segurança que hoje são cumpridos); e a lavagem e desinfeção de mãos. Com esta pandemia, foi também possível compreender que o fecho demasiado tardio esteve associado a uma maior taxa de mortalidade, o fecho mais precoce em algumas cidades implicou a existência de cidadãos suscetíveis na reabertura e que, de uma forma geral, as pessoas reagiram mais à mortalidade do que ao número de infetados em termos de cuidados de higiene (distanciamento social reativo) (Parihar, et al., 2021).

A Gripe Suína teve origem no México em 2009, propagando-se rapidamente por todo o mundo graças à facilidade da realização de viagens internacionais. Foi declarada pandemia em 2010 pela Organização Mundial de Saúde (OMS), não sendo, no entanto, tão severa como a Gripe Espanhola, dado que já existiam antivirais e devido a uma menor suscetibilidade ao vírus (Parihar, et al., 2021; Verma, et al., 2018). À semelhança do que aconteceu com a Gripe Espanhola, foram tomadas algumas medidas não farmacológicas, como o fecho de algumas escolas; a quarentena e isolamento em alguns países; e o incentivo à higienização das mãos, a ter cuidado ao tossir e ao uso de máscaras (mais comum no Leste Asiático). Com esta pandemia foi possível compreender que a maioria das mortes, neste caso, ocorreu em pessoas com menos de 65 anos (pessoas acima dos 60 anos já tinham estado expostas a estirpes semelhantes); que nos locais em que a população tenha enfrentado outros surtos, esta está mais preparada e sensibilizada; que a distribuição da vacina foi um dos aspetos fracos na resposta a esta pandemia; e que a partilha de dados foi extremamente importante para delinear e implementar estratégias 
efetivas. Por outro lado, tornou-se fundamental vigiar os animais com vista à deteção de vírus com potencial pandémico (Parihar, et al., 2021).

A Síndrome Respiratória Aguda Grave (SARS) consistiu na primeira epidemia causada por um coronavírus, sendo que a primeira infeção se registou em novembro de 2002. Apesar de possuir uma distribuição mais restrita e apresentar uma menor mortalidade do que a COVID-19, ambas apresentam características comuns, como o facto de serem causadas por um coronavírus letal, de afetarem os profissionais de saúde e de levarem à adoção de medidas semelhantes no seu combate. De facto, nas duas situações foram impostas medidas restritivas para conter os vírus, pelo que os pacientes foram colocados em quarentena e os contactos foram rastreados, sendo também sugeridas medidas protetoras que limitam a transmissão do vírus, nomeadamente, o uso de máscaras, a lavagem das mãos e o uso de substâncias desinfetantes. Com esta epidemia foi também possível tirar algumas lições, uma vez que foi possível relembrar o impacto que as doenças zoonóticas apresentam, sendo necessário estabelecer limites nos contactos entre humanos e animais. Por outro lado, foi também destacada a relevância de vigiar os profissionais de saúde, uma vez que foram fortemente afetados por esta epidemia, assim como da partilha de informação para que se possam tomar medidas eficientes e atempadas (Chau, et al., 2021; Parihar, et al., 2021).

A síndrome respiratória do Médio Oriente (MERS) foi detetada pela primeira vez em 2012, na Arabia Saudita, consistindo na segunda epidemia causada por um coronavírus. Apesar da MERS possuir baixa transmissibilidade e de permanecer restrita a alguns surtos, apresenta taxa de mortalidade elevada. Por outro lado, o vírus permanece em circulação com várias dinâmicas de transmissão, podendo mutar e ter potencial pandémico, o que justifica a preocupação em reunir mais informação sobre o mesmo. Apesar do limitado conhecimento relativamente a este vírus, pensa-se que o vírus possa ter passado para o ser humano através dos camelos, reforçando, novamente, a importância de vigiar os animais e os contactos estabelecidos entre humanos e animais. Por outro lado, esta epidemia esteve relacionada com alguns surtos em unidades de saúde, realçando, uma vez mais, a importância de os hospitais aderirem a normas de prevenção e controlo de infeção (Ebrahim, et al., 2021; Khalid, et al., 2021).

Face ao exposto, consideramos de extrema importância averiguar de que forma a história das pandemias e os ensinamentos delas retirados são ou não trabalhados em contexto de sala de aula por forma a melhorar as medidas de prevenção no futuro. 


\section{Metodologia}

No sentido de analisar como os professores abordam a $\mathrm{HC}$ nas suas aulas e de que forma a pandemia influenciou quer a abordagem da $\mathrm{HC}$, quer a atividade letiva no geral, desenvolvemos e aplicamos um inquérito por questionário (anexo 1). Este questionário foi desenvolvido pelos dois autores do artigo, sendo validado por outros dois especialistas das áreas da didática e da saúde. O questionário era constituído por 3 questões iniciais, que permitem uma pequena caracterização da amostra e 9 questões mais relacionadas com o objetivo do nosso trabalho. Destas 9 questões, 3 eram fechadas e 6 abertas no sentido de permitir uma melhor compreensão acerca das opiniões e opções tomadas pelos professores. O questionário, criado em formato digital (Microsoft Forms), foi divulgado através do email. Os professores participantes foram previamente informados dos objetivos do questionário e responderam de forma voluntária, sendo garantido o anonimato. Os resultados referentes às respostas fechadas foram analisados no Excel, com análise de frequência, sendo as respostas abertas alvo de uma análise de conteúdo, com posterior análise de frequência.

\section{Amostra}

A amostra de conveniência era constituída por 58 professores do Norte do país, com idades compreendidas entre os 34 e os 62 anos (média das idades de 51,48). Destes professores, $30(51,7 \%)$ eram do grupo de recrutamento $110\left(1^{\circ}\right.$ Ciclo do Ensino Básico), 19 (32,76\%) do grupo 520 (Biologia e Geologia), 3 do grupo 510 (Física e Química), 2 do grupo 330 (Inglês) e 1 do grupo 230 (Matemática e Ciências da Natureza), 1 do grupo 910 (Educação Especial), 1 do grupo 300 (Português) e 1 do grupo 600 (Artes Visuais).

\section{Apresentação e discussão dos resultados}

Dez dos cinquenta e oito professores inquiridos (17,2\%) referem não abordar a História da Ciência (HC) nas suas aulas. Os principais motivos, apontados por estes professores, prendem-se: com a faixa etária dos alunos (30\%), com o facto de a HC não estar contemplada no currículo/aprendizagens essenciais da disciplina em questão (50\%), pelo facto do ensino das Ciências no $1^{\circ}$ ciclo ocorrer essencialmente através de experiências $(10 \%)$ e ser explorado de forma reduzida (10\%). A este respeito, um dos inquiridos chega mesmo a referir que:

No $1 .^{\circ}$ ciclo, a aposta no ensino das Ciências é, ainda, muito limitada. E, muitas vezes, por falta de formação na área, a exploração da temática é bastante reduzida. Mas, penso que seria essencial um novo olhar para o programa de estudo do meio e uma aposta maior no ensino das Ciências e na formação docente, nesta área. (Professor 43) 
Por outro lado, a maioria dos professores inquiridos (42 - 82,8\%) refere abordar a $\mathrm{HC}$ nas suas aulas, recorrendo, essencialmente a documentários/filmes e a fichas de trabalho /análise de textos (Figura 1).

Figura 1. Principais recursos didáticos utilizados para abordar a HC.

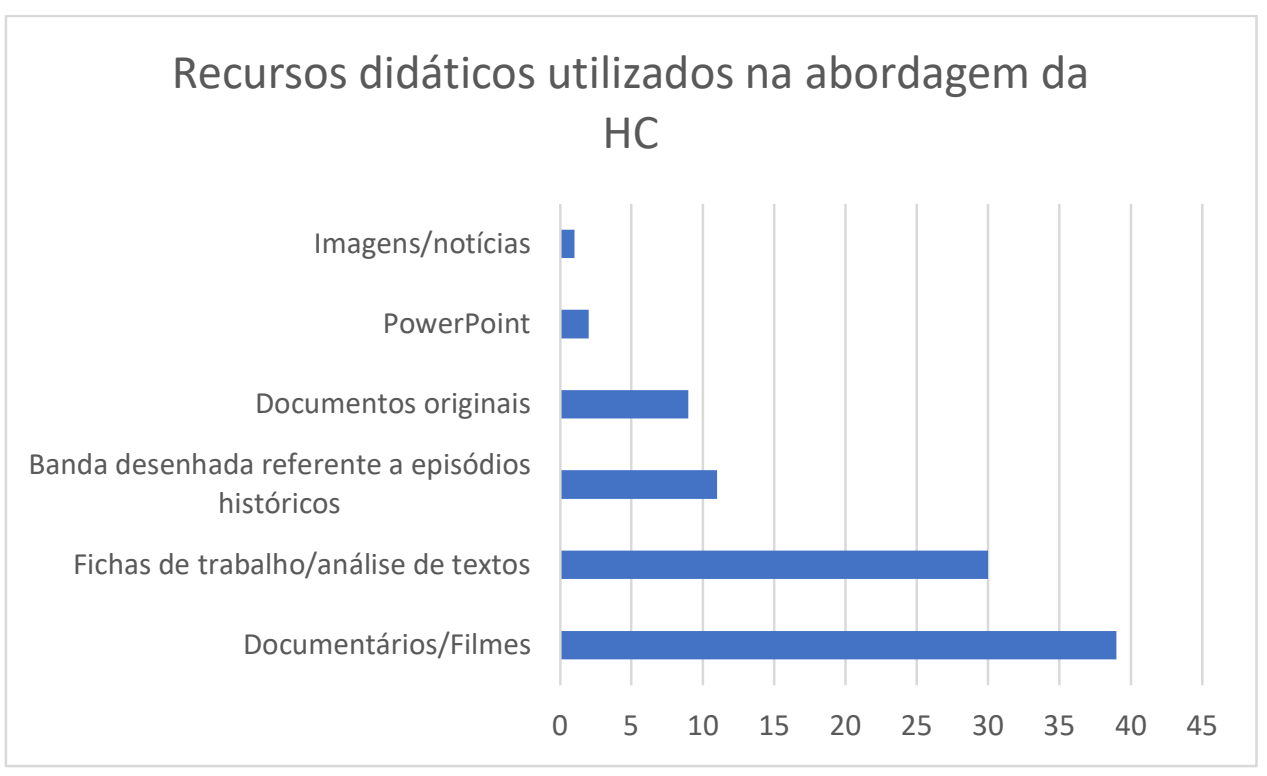

No que concerne às principais finalidades, 21 dos inquiridos referem recorrer à $\mathrm{HC}$ para que os seus alunos analisem/compreendam a evolução da ciência, sendo destacada a importância de compreender os fatores que condicionam a evolução da ciência e o contributo de vários investigadores apenas por um professor cada. 17 dos inquiridos referem que a $\mathrm{HC}$ é importante para uma melhor compreensão dos conceitos/maior atualização, sendo destacada a importância de atualmente os alunos compreenderem que já houve outras pandemias no passado, no sentido de promover uma maior consciencialização e mesmo desdramatização relativamente à nossa situação pandémica atual. Apenas 11 professores referem a importância da HC para a contextualização do desenvolvimento do conhecimento científico, 5 para a motivação dos alunos e 3 para uma melhor compreensão da importância da ciência.

Dos 48 professores inquiridos que costumam abordar a HC, 27 (56\%) referem abordar mais as questões relacionadas com a história das pandemias, face à situação pandémica que atravessamos, 19 referem abordar de igual forma e dois professores referem abordar menos estas questões. Dos 10 professores que não costumam abordar a HC, 5 (50\%) referem abordar mais as questões relacionadas com a história 
das pandemias devido à situação pandémica atual e os restantes 5 referem abordar de igual forma, ou seja, continuam sem abordar estas temáticas.

Verificou-se que as pandemias mais abordadas por estes professores em sala de aula foram: a Gripe Espanhola ( $n=26)$, a Peste Negra ( $n=25)$, a COVID-19 $(n=14)$, a Gripe Suína $(n=7)$ e a Gripe das Aves $(n=6)$. Verificou-se também que a SIDA, a Varíola e a Gripe Asiática são trabalhadas por 3, 3 e 2 professores, respetivamente.

Relativamente à recetividade dos alunos à abordagem da história das epidemias, $89,7 \%$ dos respondentes considera que os alunos se revelam interessados/recetivos. $23,1 \%$ dos respondentes revelam que os alunos manifestam curiosidade e $12,8 \%$ que os alunos participam ativamente nas tarefas propostas. A este respeito, um dos respondentes refere que:

Comparam as pandemias passadas com a atual e por vezes acham determinadas coisas parecidas (uso das máscaras por exemplo) entre outras. (Professor 25)

No que concerne às principais dificuldades sentidas na lecionação devido à situação pandémica atual, a maioria dos professores $(55-94,83 \%)$ apontou uma ou mais dificuldades, sendo que apenas 3 professores $(5,17 \%)$ referiram não existir nenhumas. Neste sentido, 14 (24,14\%) professores referiram as associadas aos meios tecnológicos, nomeadamente à falta dos mesmos e ao desconhecimento relativamente aos mesmos e $13(22,41 \%)$ apontaram a falta de interação e proximidade, como facto que dificulta, entre outras coisas, o desenvolvimento do trabalho em grupo. O uso das máscaras também foi referido por 8 professores $(13,79 \%)$ como um fator que dificulta a comunicação e aumenta o cansaço no decurso das atividades letivas, sendo a falta de participação e interesse por parte dos alunos apontada como uma dificuldade por 7 professores (12,07\%). 6 professores $(10,34 \%)$ indicam a dificuldade no acompanhamento e orientação dos alunos, uma vez que as circunstâncias inviabilizam quer a perceção das dificuldades dos alunos, quer o acompanhamento mais personalizado dos mesmos, assim como a dificuldade na realização de atividades práticas. Por outro lado, 4 professores $(6,9 \%)$ referem ainda a perda de hábitos e métodos de trabalho, 3 professores $(5,17 \%)$ a falta de autonomia dos alunos mais novos (nomeadamente dos alunos do $1^{\circ}$ ciclo), 3 professores $(5,17 \%)$ a menor concentração dos alunos, 3 professores $(5,17 \%)$ os problemas emocionais e relacionais que os alunos apresentam e 2 professores $(3,45 \%)$ a recuperação das aprendizagens. São ainda apontadas por um professor $(1,72 \%)$ dificuldades na realização de visitas de estudo, na gestão de aulas presenciais e à distância simultâneas, no cumprimento dos programas, na seleção 
dos conteúdos fundamentais, na gestão do medo e angústia dos alunos, na gestão do espaço e tempo limitados e na gestão das discrepâncias existentes entre o que é pedido nos vários estabelecimentos de ensino.

Quanto aos principais benefícios sentidos na lecionação devido à situação pandémica atual, 9 dos inquiridos $(15,52 \%)$ considera que não existiram quaisquer benefícios. Por outro lado, os restantes consideram ter existido benefícios, mormente os relacionados com os meios digitais, quer pela maior utilização e aquisição de recursos digitais, quer pelo aumento do conhecimento sobre os mesmos $(32,76 \%)$. 8 professores $(13,79 \%)$ indicaram ainda que esta situação permite que os alunos possuam maior conhecimento/ perceção da realidade e da vida e 5 professores $(8,62 \%)$ referiram que leva a uma diversificação de estratégias/adaptação às circunstâncias. A este respeito, um professor refere que:

Pensar fora da caixa. Os professores desafiarem-se a pensar fora da caixa, a procurarem novas estratégias e ferramentas para lecionar e motivar os alunos. No entanto, não o deveriam fazer apenas no ensino a distância, deveriam aproveitar estas aprendizagens para refletir, mudar e repensar o ensino e a preparação das suas aulas e em como tornar as suas aulas mais motivadoras e significativas. (Professor 43)

4 professores $(6,90 \%)$ indicaram como benefício o facto de os pais se tornarem mais cooperativos/compreensivos relativamente ao trabalho efetuado em aula, 3 professores $(5,20 \%)$ a simplificação de processos/realização de reuniões online e 2 professores $(3,45 \%)$ o maior respeito/preocupação pelos outros.

São ainda apontadas por um professor $(1,72 \%)$ o facto de o ensino ser mais interativo, de facilitar a gestão do tempo, de promover maior proximidade com os alunos, de favorecer a participação de alunos mais tímidos, de permitir uma aprendizagem "in loco", de promover o sentido de responsabilidade, de fomentar a autonomia dos alunos mais velhos, de possibilitar uma maior compreensão por parte dos alunos do esforço dos professores e de permitir que a aula decorra de um modo mais sequencial.

\section{Considerações Finais e Implicações Educacionais}

Com este estudo foi possível verificar que a maioria dos professores inquiridos refere recorrer à $\mathrm{HC}$. No entanto, quando questionados acerca das principais finalidades para recorrer à $\mathrm{HC}$, a maioria indica como motivo a compreensão da evolução do conhecimento científico e dos conceitos, sendo poucos os professores que referem a importância da compreensão da importância da Ciência, do contexto, dos fatores que condicionam a evolução da ciência e do contributo de vários investigadores. Desta feita, consideramos que seria pertinente contribuir para uma 
abordagem mais eficaz da HC, nomeadamente através da formação de professores - à semelhança do que foi indicado por um dos professores inquiridos - bem como através do desenvolvimento de materiais didáticos.

De forma geral, os professores referem abordar mais as questões relacionadas com a história das pandemias, tendo em conta o contexto em que vivemos, sendo as pandemias mais trabalhadas por estes a Gripe Espanhola, a Peste Negra e a COVID-19. Por outro lado, os professores evidenciam que, genericamente, os alunos se revelam motivados e curiosos aquando da abordagem da história das epidemias, reiterando, por isso, a relevância de a abordar em sala de aula.

Quanto à lecionação nos tempos atuais, verifica-se que, se por um lado a pandemia veio transformar o ensino, pela maior utilização, aquisição e conhecimento dos meios digitais, esta trouxe, também, algumas dificuldades relacionadas com a própria escassez e falta de conhecimento destes meios. Apesar de toda a situação pandémica ter dificultado a interação e proximidade entre os alunos e entre estes e o professor, também permitiu que os alunos percecionassem e refletissem acerca da realidade envolvente. Também obrigou a uma adaptação de professores e alunos, o que levou, por sua vez, a uma maior diversificação de estratégias, facto que poderá conduzir à melhoria dos processos de ensino e aprendizagem.

Desta forma é possível compreender que, apesar de todos os aspetos negativos que a pandemia acarreta, a inevitável transformação e adaptação que vivemos pode (e deve) também trazer benefícios a vários níveis. A nível da Educação em Ciências, em particular, defendemos que a abordagem da história das epidemias (considerada pelos professores inquiridos, como motivante para os alunos) e da pandemia atual permite trabalhar com os alunos vários aspetos, que vão desde conhecimentos e ações/medidas importantes para lidar com a situação pandémica atual, até ao desenvolvimento de conceções adequadas acerca da NdC. Estas permitem que os alunos compreendam melhor como a Ciência se desenvolve, permitindo-lhes, assim, analisar diversas situações com mais confiança e tomar decisões conscientes, responsáveis e informadas.

Através dos exemplos históricos aqui apresentados, são várias as aprendizagens que podemos retirar para os dias de hoje, sendo que a apresentação de episódios históricos e controvérsias científicas acerca da história das epidemias poderá permitir a reflexão acerca do nosso impacto na natureza, assim como acerca das medidas de restrição e importância das vacinas e dos antibióticos, entre outros.

Desta forma, os alunos estarão mais preparados para refletir e enfrentar os desafios que possam surgir! Apesar de a medicina, atualmente, nos permitir ultrapassar, com mais ou menos dificuldades, muitos dos obstáculos impostos por 
epidemias e outras doenças, também se vê confrontada com variadas problemáticas, como as doenças crónicas e demências, às quais é necessário dar resposta; as desigualdades a nível de cuidados médicos existentes entre os diversos países, a resistência microbiana e algumas condições facilitadoras da transmissão de doenças infeciosas, de que são exemplo o elevado número da população humana, a elevada densidade populacional nas cidades, o aumento das viagens internacionais e a forma como exploramos a natureza. Todos estes aspetos realçam a importância de preparar os nossos alunos para enfrentar o presente e o futuro.

\section{Referências}

Abd-El-Khalick, F. (2006). Over and over again: College students' views of nature of science. In L. B. Flick \& N. G. Lederman (Eds.), Scientific Inquiry and Nature of Science (pp. 389-425). Springer: Dordrecht, The Netherlands.

Acevedo-Díaz, J.A., \& García-Carmona, A. (2016). "Algo antiguo, algo nuevo, algo prestado". Tendencias sobre la naturaleza de la ciencia en la educación científica. Revista Eureka sobre Enseñanza y Divulgación de las Ciencias, 13(1), 3-19. http://hdl.handle.net/10498/18010

Bichara, D. B., Dagher, Z. R., \& Fang, H. (2021). What do COVID-19 Tweets Reveal about Public Engagement with Nature of Science? Science \& Education. https://doi.org/10.1007/s11191-021-00233-y

Brody, H., Rip, M. R., Vinten-Johansen, P., Paneth, N., \& Rachman, S. (2000). Mapmaking and myth-making in Broad Street: the London cholera epidemic, 1854. The Lancet, 356, 64-68. https://doi.org/10.1016/S0140-6736(00)02442-9

Callegari, M. E., Callegari, G. E., \& Cattani, A. E. (2020). La peste negra del siglo XIV en el cine. Journal of Medicine and Movies, 16, 351-361.

Chau, S. W. H., Wong, O. W. H., Ramakrishnan, R., Chan, S. S. M., Wong, E. K. Y., Li, P. Y. T., Raymont, V., Elliot, K., Rathod, S., Delanerolle, G., \& and Phiri, P. (2021). History for some or lesson for all? A systematic review and meta-analysis on the immediate and long-term mental health impact of the 2002-2003 Severe Acute Respiratory Syndrome (SARS) outbreak. BMC Public Heath, 21, 1-23. https://doi.org/10.1186/s12889-021-10701-3

Cheung, K. K. C. (2020). Exploring the Inclusion of Nature of Science in Biology Curriculum and High-Stakes Assessments in Hong Kong. Science \& Education, 29, 491-512. https://doi.org/10.1007/s11191-020-00113-x

Cook, N. (2020). Learning Lessons from history. The RoSPA OS\&H Journal, 20-25.

Dobson, C. \& Dobson, M. (2017). Plagues and History: From the Black Death to Alzheimer's Disease. In J. L. Heeney \& S. Friedemann (Eds.), Plagues (pp. 3265). Cambridge University Press. https://doi.org/10.1017/9781108147910 
Ebrahim, S. H., Maher, A. D., Kanagasabai, U., Alfaraj, S. H., Alzahrani, N. A., Alqahtani, S. A., Assiri, A. M. \& Memish, Z. A. (2021). MERS-CoV Confirmation among 6,873 suspected persons and relevant Epidemiologic and Clinical Features, Saudi Arabia - 2014 to 2019. EClinicalMedicine, 41, 1-13. https://doi.org/10.1016/j.eclinm.2021.101191

El-Dine, L. R. Z., \& Mello, V. P. S. (2021). “A gripe espanhola como lição”: a pandemia de 1918-1919 nos jornais "O Globo" e "Folha de S. Paulo" (1941-2020). Revista NUPEM, 13(29), 13-35. https://doi.org/10.33871/nupem.2021.13.29.13-35

Fernandes, M. A. F., Machado, E. A., Alves, M. P., \& Aguiar Vieira, D. (2021). Ensinar em tempos de COVID-19: um estudo com professores dos ensinos básico e secundário em Portugal. Revista Portuguesa De Educação, 34(1), 5-27. https://doi.org/10.21814/rpe.21108

Harangi-Rákos, M., Ștefănescu, D., Zsidó, K.-E., \& Fenyves, V. (2022). Thrown into Deep Water: Feedback on Student Satisfaction - A Case Study in Hungarian and Romanian Universities. Education Sciences, 12(1), 36. https://doi.org/10.3390/educsci12010036

Honigsbaum, M. (2020). The Pandemic century - A history of global contagion from the Spanish Flu to Covid-19. Random House.

Kampourakis, K. (2016). The "general aspects" conceptualization as a pragmatic and effective means to introducing students to nature of science. Journal of Research in Science Teaching, 53, 667-682. https://doi.org/10.1002/tea.21305

Khalid, I., Imran, M., Imran, M., Ali Akhtar, M., Khan, S., Amanullah, K., \& Khalid, T. J. (2021). From Epidemic to Pandemic: Comparing Hospital Staff Emotional Experience Between MERS and COVID-19. Clinical Medicine \& Research, 19(4), 169-178. https://doi.org/10.3121/cmr.2021.1657

Lederman, N.G., Abd-El-Khalick, F., Bell, R.L., \& Schwartz, R.S. (2002). Views of Nature of Science Questionnaire: Toward valid and meaningful assessment of learners' conceptions of Nature of Science. Journal of Research in Science Teaching, 39, 497-521. https://doi.org/10.1002/tea.10034

Lederman, N.G., Antink, A., \& Bartos, S. (2014). Nature of Science, Scientific Inquiry, and Socio-Scientific Issues Arising from Genetics: A Pathway to Developing a Scientifically Literate Citizenry. Science \& Education, 23, 285-302. https://doi.org/10.1007/s11191-012-9503-3

Moura, C. B., Nascimento, M. M., \& Lima, N. W. (2021). Epistemic and Political Confrontations Around the Public Policies to Fight COVID-19 Pandemic: What can Science Education learn from this episode? Science \& Education, 30, 501525. https://doi.org/10.1007/s11191-021-00193-3

OECD (2020). The impact of COVID-19 on student equity and inclusion: supporting vulnerable students during school closures and school re-openings. Retrieved January 3, 2022, from https://bit.ly/3rfYelq

Parihar, S., Kaur, R. J., \& Singh, S. (2021). Flashback and lessons learnt from history of pandemics before COVID-19. Journal of Family Medicine and Primary Care, 10(7), 2441-2449. 
Raoult, D., Dutour, O., Houhamdi, L., Jankauskas, R., Fournier, P., Ardagna, Y. Drancourt, M., Signoli, M., Dang La, V., Macia, Y. Aboudharam, G. (2006). Evidence for Louse-Transmitted Diseases in Soldiers of Napoleon's Grand Army in Vilnius. The Journal of Infectious Diseases, 193, 112-120.

Reiss, M. J. (2020). Science Education in the Light of COVID-19. Science \& Education, 29, 1079-1092. https://doi.org/10.1007/s11191-020-00143-5

Revel Chion, A., \& Adúriz-Bravo, A. (2021). In Sickness and in Health. Science \& Education. https://doi.org/10.1007/s11191-021-00258-3

Roos, J. (2020). How plagues change the world. The New Statesman, 149(5520), 2428.

Smith, K. A. (2011). Edward Jenner and the small pox vaccine. Frontiers in Immunology, 2(21), 1-6. https://doi.org/10.3389/fimmu.2011.00021

Toapanta, H. G. G. (2021). Pandemias en la historia: La peste negra y la gripe española, covid-19 y crisis capitalista. Revista de Ciencias Sociales y Humanidades, 14, 130-145.

Tognotti, E. (2013). Lessons from the History of Quarantine, from Plague to Influenza A. Emerging Infectious Diseases, 19(2), 254-259. https://doi.org/10.3201/eid1902.120312

Torres, J. \& Vasconcelos, C. (2015). Nature of science and models: Comparing Portuguese prospective teachers' views. Eurasia Journal of Mathematics, Science \& Technology Education, 11(6), 1473-1494. https://doi.org/10.12973/eurasia.2015.1407a

Torres, J. (2021). História das epidemias. In Caderno de Resumos - VIII Jornada de História da Ciência e Ensino e II Congresso Internacional de História da Ciência no Ensino. Revista História da Ciência e Ensino, vol 23 (suplemento), p. 15. 2629 outubro.

Torres, J., \& Vasconcelos, C. (2021). Models and the Nature of Science: What Mediates Their Implementation in Portuguese Biology and Geology Classes? Education Sciences, 11, 688. https://doi.org/10.3390/educsci11110688

Verma, R., Chayal, V., Kumar, R., Bhalla, K., Dhankar, M., Dhaka, R., Agrawal, G. (2018). Community perception about swine flu in an urban slum of Haryana: A cross-sectional study. Journal of Family Medicine and Primary Care, 7(6), 15151520. https://doi.org/10.4103/jfmpc.jfmpc 151_18

Villar, A. M. (2020). Remedios curativos y propaganda médica contra la influenza de 1918 en México: ideas y conocimientos. História, Ciências, Saúde-Manguinhos, 27(2), 391-409. https://doi.org/10.1590/S0104-59702020000200005

World Health Organization (WHO). (2020). Coronavirus disease 2019 (COVID-19) Situation Report - 51. 
Anexo 1

\section{Questionário \\ Pandemia e abordagem da História da Ciência}

Caro(a) professor(a), este questionário tem como principal objetivo compreender de que forma a pandemia influenciou a abordagem da História da Ciência nas suas aulas.

Não havendo respostas certas nem erradas, pedimos que responda a todas as questões possíveis de forma sincera.

Agradecemos desde já a sua colaboração.

1. Por favor, indique a sua idade:

2. Grupo de recrutamento:

110

230

500
510

520

Outro: Qual?

3. Anos de serviço:

\section{Pandemia e abordagem da História da Ciência}

4. Nas suas aulas, costuma abordar a História da Ciência?

Sim

Não

5. Se respondeu afirmativamente à questão anterior, indique quais os principais recursos didáticos/atividades que utiliza para abordar a história da ciência.

Fichas de trabalho/análise de textos

Documentários / Filmes

Análise de documentos originais

Análise de banda desenhada referente a episódios históricos Outro. Qual/Quais?

6. Se respondeu afirmativamente à questão quatro, indique com que finalidade(s) recorre à história da ciência. 
7. Se respondeu negativamente à quarta questão, indique por que motivo não recorre à história da ciência.

8. Devido à situação de pandemia que estamos a atravessar, a História da Ciência associada a esta temática (Pandemias) tem sido...

_...mais abordada nas suas aulas. ...menos abordada nas suas aulas. ....abordada de igual forma nas suas aulas.

9. Se tem recorrido à história das pandemias nas suas aulas, refira algumas (até 3) das pandemias que tem vindo a trabalhar.

10. Se tem recorrido à história das pandemias nas aulas, na sua opinião, qual a recetividade dos alunos à abordagem desta temática (história das pandemias)?

11. Quais as principais dificuldades sentidas na lecionação devido à situação pandémica atual?

12. Quais os principais benefícios sentidos na lecionação devido à situação pandémica atual? 